\title{
Preparation and Catalytic Properties of Ti-SBA-15 Mesoporous Materials
}

\author{
Wenhao Ye, Zheng Lin, Beibei Dong, Jinfeng Kang, Xiucheng Zheng*, Xiangyu Wang
}

Department of Chemistry, Zhengzhou University, Zhengzhou, China.

Email:*zhxch@zzu.edu.cn

Received November $15^{\text {th }}, 2010$; revised December $29^{\text {th }}, 2010$; accepted May $17^{\text {th }}, 2011$.

\begin{abstract}
Ti-SBA-15 mesoporous materials were directly synthesized via a hydrothermal process and characterized by using nitrogen adsorption-desorption measurements, X-ray diffraction, scanning electron microscopy, transmission electron microscopy, diffuse reflectance ultraviolet-visible spectroscopy, and infrared ray spectroscopy. The effect of synthesis temperatures on the structure and catalytic efficiency in epoxidation of cyclohexene was discussed in details. The results showed that the optimal temperature was $100^{\circ} \mathrm{C}$ under the reaction conditions.
\end{abstract}

Keywords: Ti-SBA-15; Hydrothermal Synthesis, Synthesis Temperatures, Cyclohexene, Epoxidation

\section{Introduction}

It is known that epoxidation reactions of alkenes generally require the presence of a catalyst. However, several side reactions can take place, such as oxidation in the allylic positions, ring-opening of the epoxides by hydrolysis or solvolysis, epoxide rearrangement, or even total break-down of the $\mathrm{C}=\mathrm{C}$ double bonds [1]. Cyclohexene epoxidation to yield cyclohexene oxide is one of the most difficult cases, in which the first two problems, namely allylic oxidation and epoxide ring-opening, occur considerably. Cyclohexene oxide is an important organic intermediate consumed in the production of pharmaceuticals, plant-protection agents, pesticides, and stabilizers for chlorinated hydrocarbons. Therefore, it is very essential and vital to develop new active and selective cyclohexene epoxidation catalysts that circumvent the side reactions and the subsequent formation of large amounts of by-products [2].

On the other hand, mesoporous molecular sieves have attracted great interest in many fields, such as catalysis and materials science, since their disclosure in 1992 [3]. The most important features for their use are the extremely high surface area and well defined pore size which can be adjusted over a large range $(2-20 \mathrm{~nm})$. However, pure mesoporous molecular sieves have no intrinsic catalytic activity. It is necessary to replace part of the silicon of the structure or graft onto the internal surface of the pores heteroatoms such as Al, Ti, W or Mo which are able to make the solids catalytically active [4].
In particular, titania modified silica takes advantages of titania and mesoporous silica, making it more active, stable and easier to recover [5]. To date, much effort has been made to the study of the catalytic efficacy of mesoporous molecular sieves containing titanium. For example, Galacho et al. [6] prepared Ti-MCM-41 at ambient temperature and pressure and evaluated their catalytic activities in the reaction of oxidation of cyclohexene. They found that the sample with $\mathrm{Si} / \mathrm{Ti}=10$ exhibited the highest conversion and excellent selectivity. Eimer et al. [7] studied the influence of Ti-loading on the acid behavior and the catalytic efficiency in the oxidation of cyclohexene of Ti-MCM-41. The results showed that the reaction presented a high velocity during the 1 st hours and cyclohexene epoxide was the main product.

Siliceous mesoporous materials SBA-15 possess a regular two-dimensional array of tubular channels $[8,9]$. In comparison with the other regular mesoporous materials, SBA-15 can be prepared with larger pores, resulting in a more stable structure because of thicker pore walls. Hence, SBA-15 have recently attracted considerable attention because of the promising applications in shapeselective catalysis, separations involving large molecular, etc [10]. As we all know, the catalytic properties of the catalysts are affected greatly by their composition, structure, preparation method, and process treatment. Scholars have done many studies in the case of functionalization of SBA-15 materials with isolated titanium sites, such as Reference $[11,12]$. However, to the best of our knowledge, 
only a few researches have been done on the direct synthesis and catalytic properties of Ti-SBA- 15 in the reaction of cyclohexene oxidation to yield cyclohexene epoxide.

The aim of the present work was to study the influence of synthesis temperatures on the structure and catalytic properties of Ti-SBA-15 composite prepared by a directly hydrothermal process. The physiochemical properties were investigated by using nitrogen adsorption-desorption measurements $\left(\mathrm{N}_{2}\right.$ sorption), X-ray diffraction (XRD), scanning electron microscopy (SEM), transmission electron microscopy (TEM), diffuse reflectance ultraviolet-visible spectroscopy (DR UV-vis), and infrared ray spectroscopy (IR). The catalytic properties of TiSBA-15 were tested for the cyclohexene epoxidation reaction with tert-butyl hydroperoxide (TBHP). The results will be helpful for the development of the study of mesoporous materials and epoxidation reactions.

\section{Experimental}

\subsection{Catalysts Preparation}

Ti-SBA-15 composite catalysts were prepared by directly hydrothermal synthesis using Pluronic P123 triblock polymer $\left(\mathrm{EO}_{20} \mathrm{PO}_{70} \mathrm{EO}_{20}, \mathrm{M}_{\mathrm{av}}=5800\right.$, Aldrich) as structure-directing reagent. Tetraethoxysilane (TEOS) and titanium isopropoxide (TIP) were used as the $\mathrm{Si}$ and $\mathrm{Ti}$ sources, respectively. $1.00 \mathrm{~g}$ of P123 was added to 35.00 $\mathrm{mL}$ of $1.72 \mathrm{~mol} / \mathrm{L} \mathrm{HCl}$ solution to yield a transparent solution at $40^{\circ} \mathrm{C}$. Then $2.30 \mathrm{~mL}$ of tetraethylorthosilicate (TEOS) and $0.34 \mathrm{~mL}$ mixed solution of acetylacetone and TIP (molar ratio 1:1) were added dropwise and the solution was stirred for another $24 \mathrm{~h}$. The prepared gel was transferred into Teflon-lined stainless-steel autoclave and crystallized at different temperatures $(80,100,120$, 140 , and $160^{\circ} \mathrm{C}$, respectively) for $24 \mathrm{~h}$. The final solid was filtered, washed with $\mathrm{H}_{2} \mathrm{O}$ and dried at $110^{\circ} \mathrm{C}$ overnight. Finally, the samples were calcined at $500^{\circ} \mathrm{C}$ for $6 \mathrm{~h}$.

Pure SBA-15 synthesized at $100^{\circ} \mathrm{C}$, herein, was also prepared with the same method for the comparison purpose.

\subsection{Catalysts Characterization}

$\mathrm{N}_{2}$ adsorption-desorption experiments were performed with a Quantachrome NOVA 1000e surface area \& pore size analyzer. Before measurement, the samples were degassed at $150^{\circ} \mathrm{C}$ under vacuum $(1.33 \mathrm{~Pa})$ for $1.5 \mathrm{~h}$. The specific surface area of samples was determined using the Brunauer-Emmett-Teller (BET) method. The total pore volume was evaluated at a relative pressure about 0.99 . The pore size distributions were derived from the desorption profiles of the isotherms using the Barrett-
Joyner-Halenda (BJH) method, based on the Kelvin equation [13].

Low-angle X-ray powder diffraction (XRD) patterns were collected on a PW3040/60 diffractometer using $\mathrm{Cu}$ $\mathrm{K} \alpha$ radiation of wavelength $0.15418 \mathrm{~nm}$. Diffraction data were recorded at an interval of 0.01671 in the $2 \theta$ range of $0.5^{\circ}-5^{\circ}$. The interplanar distance $\left(\mathrm{d}_{100}\right)$ was obtained by the Bragg's law using the position of the first X-ray diffraction line. Large-angle XRD patterns of the samples were recorded with the same diffractometer in the $2 \theta$ range of $10^{\circ}-80^{\circ}$.

Scanning electron microscopy (SEM) images were taken using a HITACHI S4800 scanning electron microscope. For the SEM observations, the samples were deposited on a sample holder and coated with $\mathrm{Au}$, using an accelerating voltage of $10.0 \mathrm{kV}$.

The transmission electron microscopy (TEM) measurements were performed on Tecnai G2F20 (USA) to observe the inner pore structure of samples.

IR spectra were recorded on a Thermoscientific Nicolet 380 FT-IR spectrometer at $2 \mathrm{~cm}^{-1}$ resolution using a $\mathrm{KBr}$ pellet technique. Before measurement, all samples and $\mathrm{KBr}$ were dried in loft drier at $373 \mathrm{~K}$ overnight. The sample diluted in $\mathrm{KBr}(2.0 \mathrm{wt} \%)$ was pressed into a wafer ( $40.5 \mathrm{mg} \cdot \mathrm{cm}^{-2}$ thickness). The spectra were collected in transmittance mode.

Diffuse reflectance UV-vis spectra were collected on a Hitachi U-3010 UV-vis spectrophotometer in the 200 $800 \mathrm{~nm}$ range with a resolution of $1.0 \mathrm{~nm} . \mathrm{BaSO}_{4}$ was used as reference for measurements.

\subsection{Catalytic Experiments}

The catalytic efficiency studies were carried out using cyclohexene as substrate and TBHP as the primary oxidant. In a typically reaction, $50 \mathrm{~mL}$ round-bottomed flask was fitted with a reflux condenser and placed in a constant temperature oil bath. $5.0 \mathrm{~mL}$ of cyclohexene, 20.0 $\mathrm{mL}$ of solvent (1, 2 Dichloroethane), $4.0 \mathrm{~mL}$ of TBHP, and $0.25 \mathrm{~g}$ of Ti-SBA- 15 composite catalyst was added into the flask, respectively. Products were analyzed by a gas chromatography equipped with a capillary column $(\mathrm{KF} 1701,30 \mathrm{~m} \times 0.2 \mathrm{~mm} \times 0.5 \mu \mathrm{m})$ and a flame ionization detector (FID).

\section{Results and Discussion}

Low-angle XRD analysis is an effective probe for the meso-structure materials. Figure 1 shows the low-angle XRD patterns of pure SBA-15 and Ti-SBA-15 samples. It can be seen that all the samples exhibited XRD patterns with one very intense diffraction peak and two weak peaks, which are characteristic of 2-D hexagonal (P6mm) structure with excellent textural uniformity. The results indicated that Ti-SBA-15 composite catalysts 


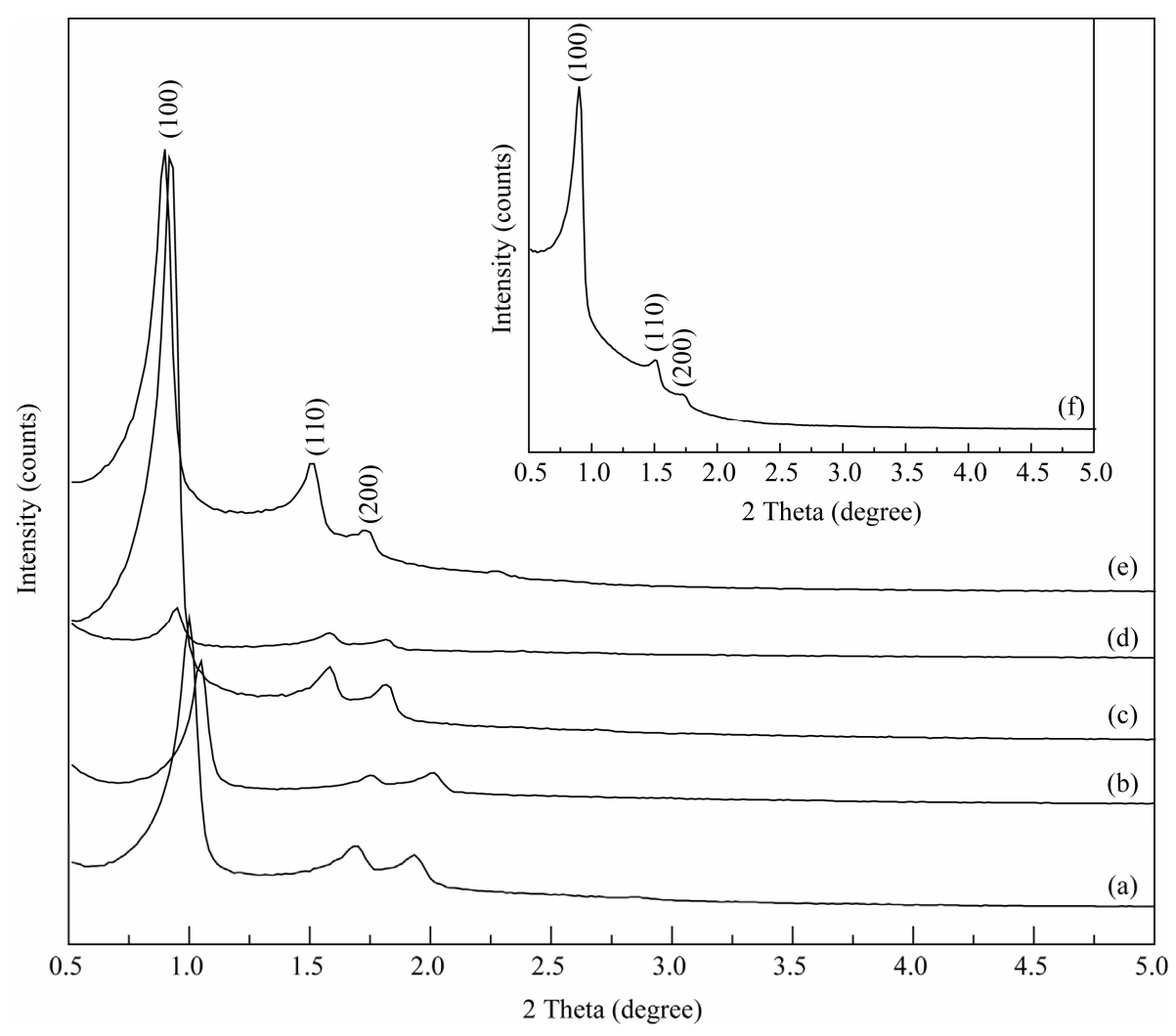

Figure 1. Low-angle XRD patterns of pure SBA-15 (a) and Ti-SBA-15 synthesized at different temperatures: (b) $80^{\circ} \mathrm{C}$, (c) $100^{\circ} \mathrm{C}$, (d) $120^{\circ} \mathrm{C}$, (e) $140^{\circ} \mathrm{C}$, (f) $160^{\circ} \mathrm{C}$.

retained the ordered mesoporous structure of SBA-15. Moreover, compared with pure SBA-15, there was a shift towards lower angles for the characteristic peaks of the Ti-SBA-15 composite except for the one synthesized at $80^{\circ} \mathrm{C}$. This may indicate that the pore diameter increased when titanium oxide is introduced into silica due to the fact that the Ti-O bond is longer than that of Si-O, similar to that of W-SBA-15 [14]. However, as seen in Figure If (insert), when the temperature rose up to $160^{\circ} \mathrm{C}$, the relative intensity of the (110) and (200) peaks decreased. The results clearly indicated that the synthesis temperatures remarkably affected the structure. In other words, although the ordered mesoporous structure of SBA-15 are retained at low crystallization temperature, higher temperature leads to some disruption of the structure.

Figure 2 shows the large-angle XRD pattern of Ti-SBA- 15 composite synthesized at $100^{\circ} \mathrm{C}$. Only a single broad peak appeared at about $22.7^{\circ}$ characteristic of amorphous silica [12]. The characteristic peaks of an anatase structure associated with $\mathrm{TiO}_{2}$ are not present in the pattern. This suggests that $\mathrm{TiO}_{2}$ was in the fine dispersion state and no obvious crystallites were formed.

Figure 3 shows the SEM micrographs of pure SBA-15 and Ti-SBA-15 composite synthesized at $100^{\circ} \mathrm{C}$. The micrographs reveal that the Ti-SBA-15 retained the

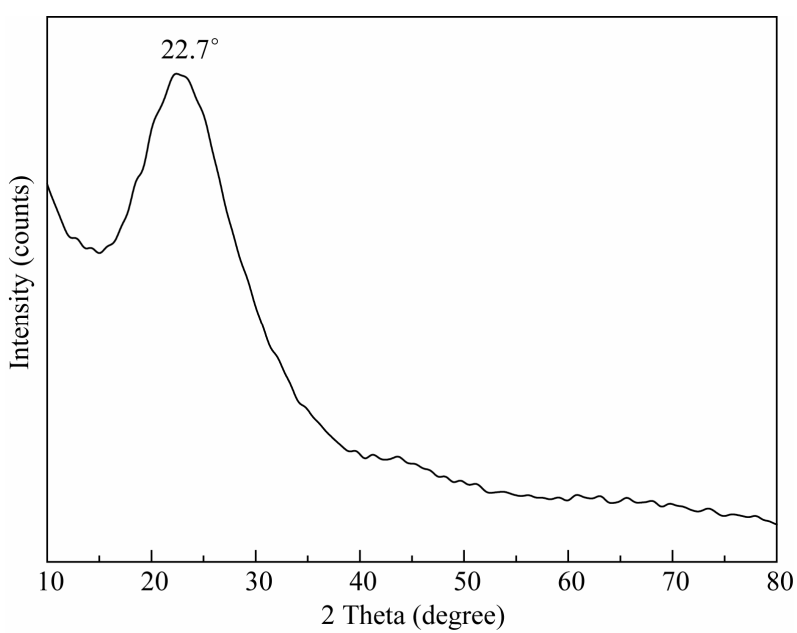

Figure 2. Large-angle XRD pattern of Ti-SBA-15 synthesized at $100^{\circ} \mathrm{C}$.

well-defined wheat-like macro-structure of pure SBA-15 [14]. And the relatively uniform particles sizes were about of $4-6 \mu \mathrm{m}$. However, although no strong characteristic peaks of crystalline $\mathrm{TiO}_{2}$ appeared in XRD patterns as shown in Figure 2 and the rope-like domains were still largely maintained, a significant degradation in macroscopic structure can be observed, suggesting that 


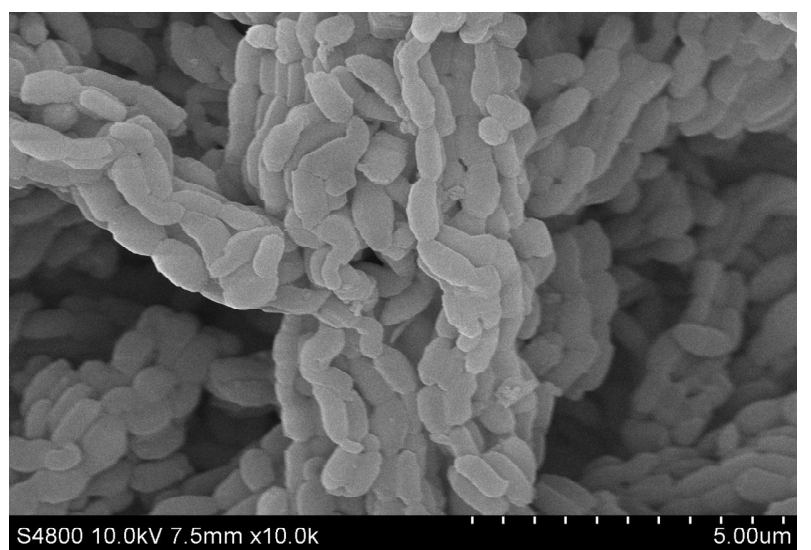

(a)

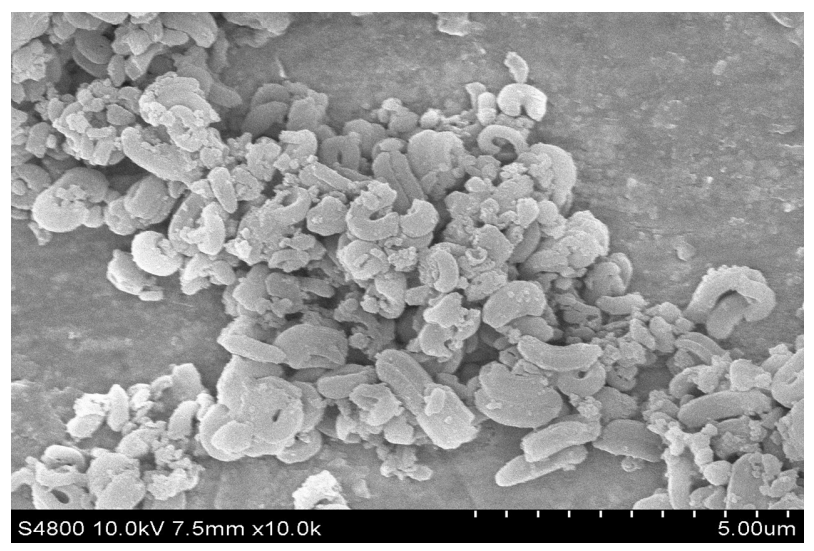

(b)

Figure 3. SEM micrographs of pure SBA-15 (a) and Ti-SBA-15 synthesized at $100^{\circ} \mathrm{C}(\mathrm{b})$.

titanium oxide begins to congregate.

TEM was furthermore applied to investigate the interior of the prepared Ti-SBA-15 composite materials. Figure 4 shows the micrographs viewed normal to or along the axis of the hexagonal pores of Ti-SBA-15 composite synthesized at $80^{\circ} \mathrm{C}$ and $140^{\circ} \mathrm{C}$, respectively. The images clearly indicated that both the samples retained the characteristic p6mm structure of pure SBA-15. Furthermore, as indicated in Figure 4, the pore size of Ti-SBA-15 synthesized at $140^{\circ} \mathrm{C}$ was remarkably larger than that of the sample synthesized at $80^{\circ} \mathrm{C}$.

Figure 5 shows the forms of the nitrogen adsorptiondesorption isotherms and pore size distributions of Ti-SBA-15 composite materials. All the curves are type IV in the classification of Brunauer with H1-type hysteresis loops. This also suggested that the doping of titanium species retained the typical mesoporous structure of SBA-15. Comparing with the others, the hysteresis loop of Ti-SBA-15 synthesized at $80^{\circ} \mathrm{C}$ appeared at low relative pressure (between 0.50 and 0.85 ), indicating the smallest pore size. Furthermore, the hysteresis loops

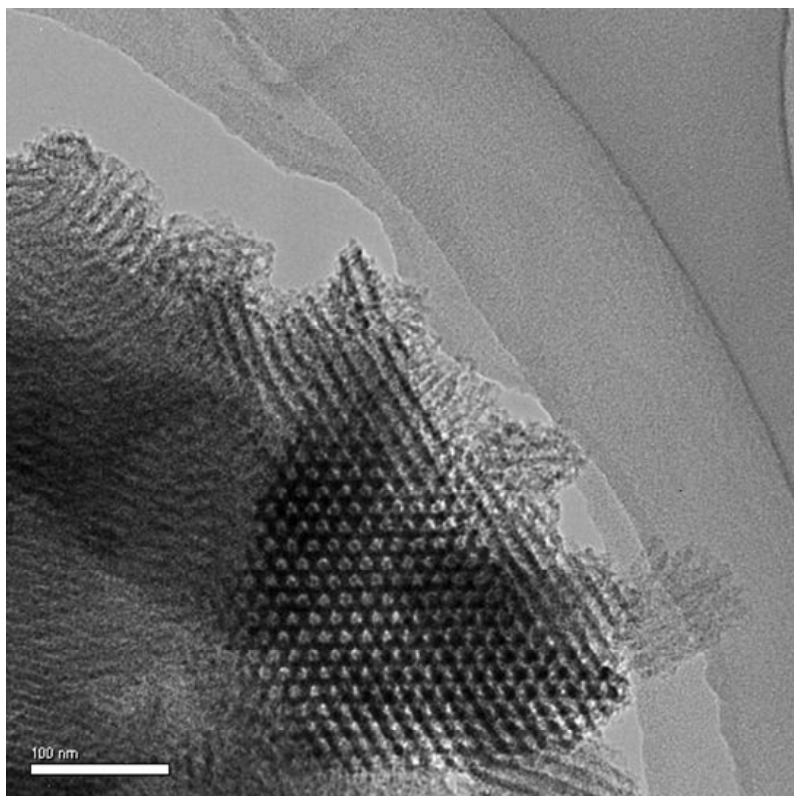

(a)

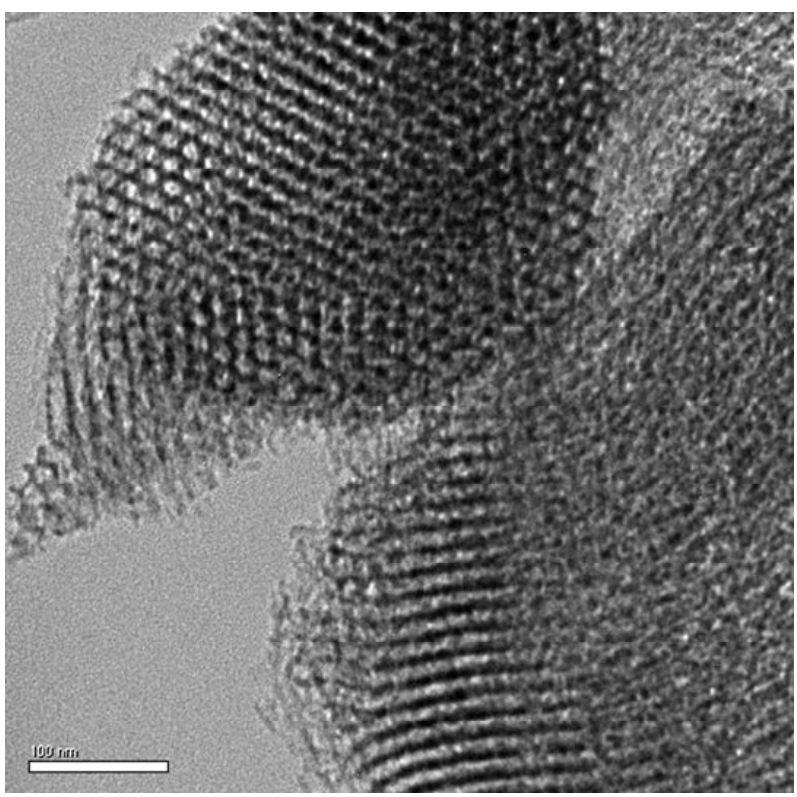

(b)

Figure 4. TEM micrographs of Ti-SBA-15 synthesized at $80^{\circ} \mathrm{C}$ (a) and $140^{\circ} \mathrm{C}(\mathrm{b})$.

moved slightly to higher relative pressure with the increase of synthesis temperatures under the present conditions. This revealed that the pore size increased with the increase of synthesis temperatures as mentioned in Table 1. It is noteworthy that the curves of pore size distribution for the sample synthesized at low temperatures $\left(80^{\circ} \mathrm{C}\right.$ and $\left.100^{\circ} \mathrm{C}\right)$ exhibited relatively narrower than the others (Figure 5(B)).

Table 1 summarizes the structure properties of the 


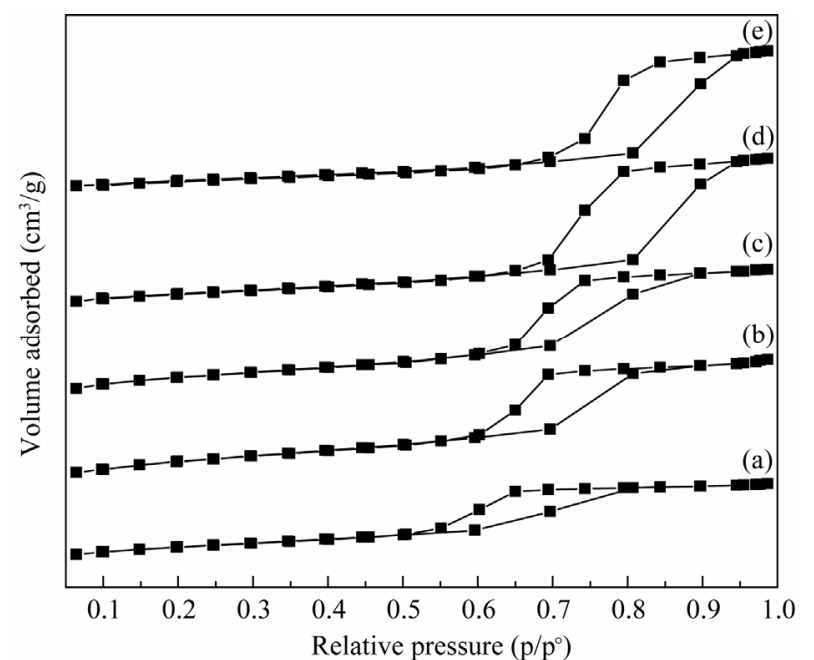

(A)

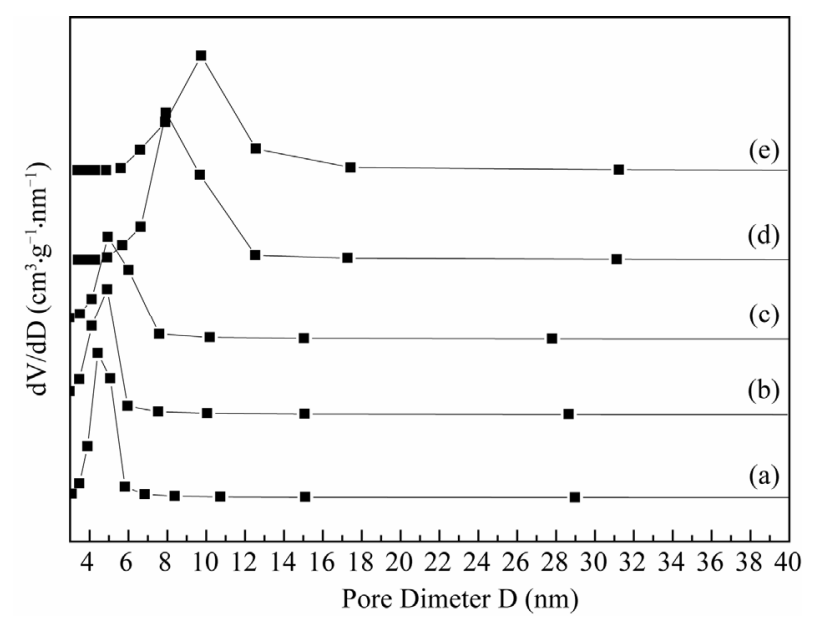

(B)

Figure 5. $\mathrm{N}_{2}$ adsorption-desorption isotherms (A) and pore size distributions (B) of Ti-SBA-15 synthesized at different temperatures: (a) $80^{\circ} \mathrm{C}$, (b) $100^{\circ} \mathrm{C}$, (c) $120^{\circ} \mathrm{C}$, (d) $140^{\circ} \mathrm{C}$, (e) $160^{\circ} \mathrm{C}$.

prepared Ti-SBA-15 composite materials. As it can been seen from Table 1, the value of surface area, pore volume, pore size, cell parameter and wall thickness for the sample synthesized at $100^{\circ} \mathrm{C}$ were higher than those for the one synthesized at $80^{\circ} \mathrm{C}$. When the synthesis temperatures increased further, the value of surface area, and wall thickness, especially Ti-SBA-15 synthesized at $160^{\circ} \mathrm{C}$, decreased obviously. Meanwhile, the mean pore size increased greatly with only a little change of pore volume and cell parameter. The results clearly indicated that the crystallization temperature affected the pore structure greatly. As we all know, wall thickness of mesoporous materials is a key factory to ensure its hydrothermal stability. Therefore, $100^{\circ} \mathrm{C}$ was the optimal crystallization temperature under the reaction conditions.
It is known that diffuse reflectance UV-vis (DR UV-vis) spectroscopy is a very sensitive probe for the presence of extra-framework transition metal oxides in different heteroatomic mesostructures [14,15]. Hence, we used UV-vis spectroscopy to characterize the coordination and the chemical nature of the titanium species in the prepared Ti-SBA-15 samples. According to the Reference [16-18], the existence of titanium (IV) isolated in the framework was characterized by a band at about 210 $230 \mathrm{~nm}$ for a tetrahedral environment and $240-250 \mathrm{~nm}$ for an octachedral environment. Chiker et al. [12] reported that the formation of titanium oxide clusters in the anatase form leads to a displacement of the band towards higher wavelengths. In other words, the absorption threshold for anatase is at about $350 \mathrm{~nm}$. Other scholars $[14,15,19,20]$ reported that the band centered at about $220 \mathrm{~nm}$ implies the presence of a ligand-to-metal charge transfer involving isolated transition metal sites, and is generally considered direct proof that transition metal atoms have been incorporated into the framework of a molecular sieve.

The DR UV-vis spectra of Ti-SBA-15 composite in the region of $200-800 \mathrm{~nm}$ are depicted in Figure 6. The spectrum of pure SBA-15 was also included for comparison purposes. As can be seen from Figure 6, pure SBA-15 had no characteristic absorbance band. While the curves of the Ti-SBA-15 composite exhibited significant bands. It is noteworthy that when the synthesis temperature was low, the relative intensity of the band at ca. $220 \mathrm{~nm}$ was high, indicating titanium species successfully incorporated into the framework SBA-15 with the presence in tetrahedral coordination. However, the relative intensity of the band in the region of $280-380$ $\mathrm{nm}$ related to anatase increased with the increase of synthesis temperatures (e.g. $160^{\circ} \mathrm{C}$ ). Meanwhile, the band at ca. $240 \mathrm{~nm}$ related to octachedral coordination environment became clear. The results indicated that the effect of synthesis temperatures on the nature and the dispersion of the titanium species were obvious. Oki et al. [21] reported that $\mathrm{Ti}-\mathrm{O}-\mathrm{Si}$ was the active center for catalysis. Therefore, lower synthesis temperatures (e.g. 80 and $100^{\circ} \mathrm{C}$ ) promoted the form of the active center Ti-O-Si.

The fourier transform infrared (FT-IR) spectra of pure SBA-15 and Ti-SBA-15 composite materials are shown in Figure 7. The bands around $3440 \mathrm{~cm}^{-1}$ can be assigned to the $\mathrm{O}-\mathrm{H}$ stretching vibrations mode of the silanols involved in hydrogen interactions with the adsorbed water molecules [22]. The band at ca. $1080 \mathrm{~cm}^{-1}$ and 810 $\mathrm{cm}^{-1}$ corresponded to characteristic of anti-symmetric vibration nonbridging oxygen atoms $\left(\mathrm{Si}-\mathrm{O}^{\delta^{-}}\right)$of $\mathrm{Si}-\mathrm{O}-\mathrm{H}$ bonds and symmetric stretching vibration $(\mathrm{Si}-\mathrm{O}-\mathrm{Si})_{\text {sym }}$ of tetrahedral $\mathrm{SiO}_{4}$ structure units [23]. Meanwhile, the band at ca. $459 \mathrm{~cm}^{-1}$ corresponded to characteristic of 
Table 1. Pore structure parameters of the prepared Ti-SBA-15 samples.

\begin{tabular}{ccccccc}
\hline $\begin{array}{c}\text { Synthesis } \\
\text { temperatures }\left({ }^{\circ} \mathrm{C}\right)\end{array}$ & BET area $\left(\mathrm{m}^{2} \cdot \mathrm{g}^{-1}\right)$ & Pore volume $\left(\mathrm{cm}^{3} \cdot \mathrm{g}^{-1}\right)$ & Pore size $D(\mathrm{~nm})$ & $\mathrm{d}_{100}(\mathrm{~nm})$ & $a_{0}{ }^{\mathrm{a}}(\mathrm{nm})$ & $\begin{array}{c}\text { Wall thickness } \\
t^{\mathrm{b}}(\mathrm{nm})\end{array}$ \\
\hline 80 & 557.3 & 0.67 & 4.8 & 8.41 & 9.71 & 4.91 \\
100 & 754.5 & 1.01 & 5.4 & 9.52 & 10.99 & 5.99 \\
120 & 610.0 & 0.98 & 6.4 & 9.28 & 10.72 & 4.32 \\
140 & 454.1 & 1.08 & 9.5 & 9.83 & 11.35 & 1.85 \\
160 & 362.1 & 1.00 & 11.1 & 9.78 & 11.29 & 0.19 \\
\hline
\end{tabular}

${ }^{\mathrm{a}}: a_{0}=\frac{2 d_{100}}{\sqrt{3}} \cdot{ }^{\mathrm{b}}: t=a_{0}-D$

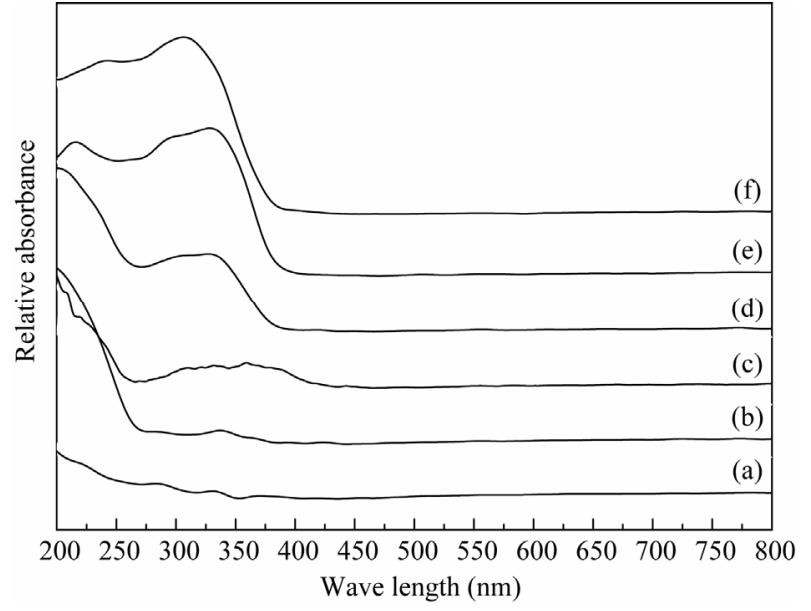

Figure 6. DR UV-vis spectra of pure SBA-15 (a) and TiSBA-15 synthesized at different temperatures: (b) $80^{\circ} \mathrm{C}$, (c) $100^{\circ} \mathrm{C}$, (d) $120^{\circ} \mathrm{C}$, (e) $140^{\circ} \mathrm{C}$, (f) $160^{\circ} \mathrm{C}$.

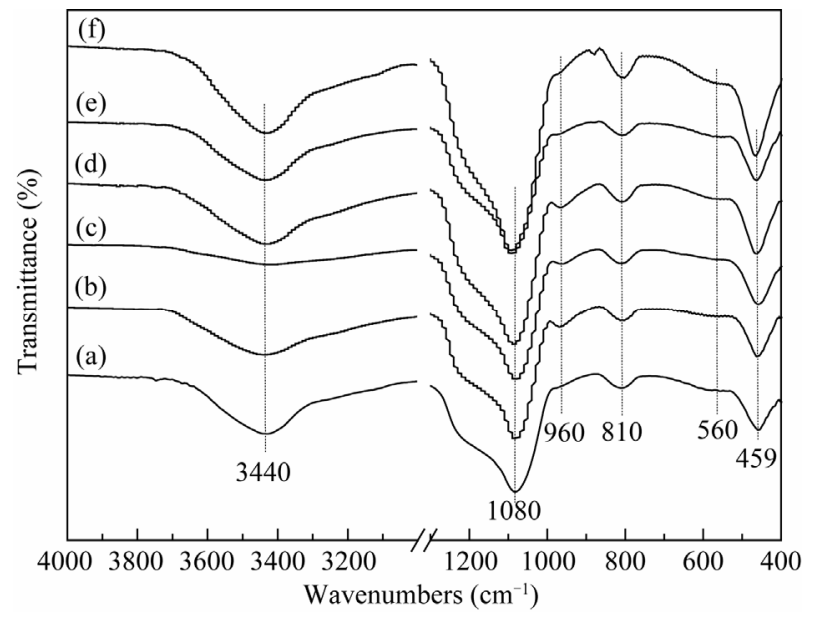

Figure 7. FT-IR spectra of pure SBA-15 (a) and Ti-SBA-15 synthesized at different temperatures: (b) $80^{\circ} \mathrm{C}$, (c) $100^{\circ} \mathrm{C}$, (d) $120^{\circ} \mathrm{C}$, (e) $140^{\circ} \mathrm{C}$, (f) $160^{\circ} \mathrm{C}$.

tetrahedral bending of Si-O bonds [24]. No typical IR band located at around $960 \mathrm{~cm}^{-1}$ can be observed for the pure SBA-15. However, Ti-SBA-15 exhibits a strong band, especially for the samples synthesized at low temperatures $\left(80^{\circ} \mathrm{C}-120^{\circ} \mathrm{C}\right)$, at around $960 \mathrm{~cm}^{-1}$.

The band at around $960 \mathrm{~cm}^{-1}$ has been widely used to characterize the incorporation of metal ions in the silica framework as the stretching $\mathrm{Si}-\mathrm{O}$ vibration mode perturbed by the neighboring metal ions [25,26]. According to Gao et al. [27] and Kochkar et al. [28], the Ti-O-Si infra-red vibration is generally observed between 910 and $960 \mathrm{~cm}^{-1}$, with the exact band position depending on the chemical composition of the sample as well as calibration and resolution of the instrument. Therefore, the presence of the band at ca. $960 \mathrm{~cm}^{-1}$ is a piece of direct evidence for the isomorphous substitution of $\mathrm{Si}$ by $\mathrm{Ti}$ ions in Ti-SBA-15.

In addition, the appearance of a weak band at ca. 560 $\mathrm{cm}^{-1}$, characteristic band for Titania $\left(\mathrm{TiO}_{2}\right)$ in the Ti-SBA-15 synthesized at $160^{\circ} \mathrm{C}$ may be an indication of the appearance of the titania phase [29]. This was consistent with that of UV-vis results mentioned above.

Experiments approved that the conversion of cyclohexene can be as high as $88 \%-95 \%$ over all the present Ti-SBA-15 composite materials under the reaction conditions. Here, the catalytic efficiencies of Ti-SBA-15 composite materials for cyclohexene epoxidation as a function of reaction time in the region of 1 - 10 hours are presented in Figure 8. It is generally acknowledged that the selectivity of cyclohexene epoxide increased significantly with the increase of reaction time under the reaction conditions for all the present catalysts. In addition, our experiment exhibited that the by-products of the catalytic reaction were 2-cyclohexen-1-ol, 2-cyclohexenone, and 2-tert-butyl-cyclohexen.The GC-MS analytic results showed that the percent of by-products decreased with the increase of reaction time. Meanwhile, the percent of cyclohexene epoxide increased.

Furthermore, it is clear from Figure 8 that the catalytic efficiency varies with the synthesis temperatures. TiSBA-15 synthesized at $100^{\circ} \mathrm{C}$ exhibited slightly higher 


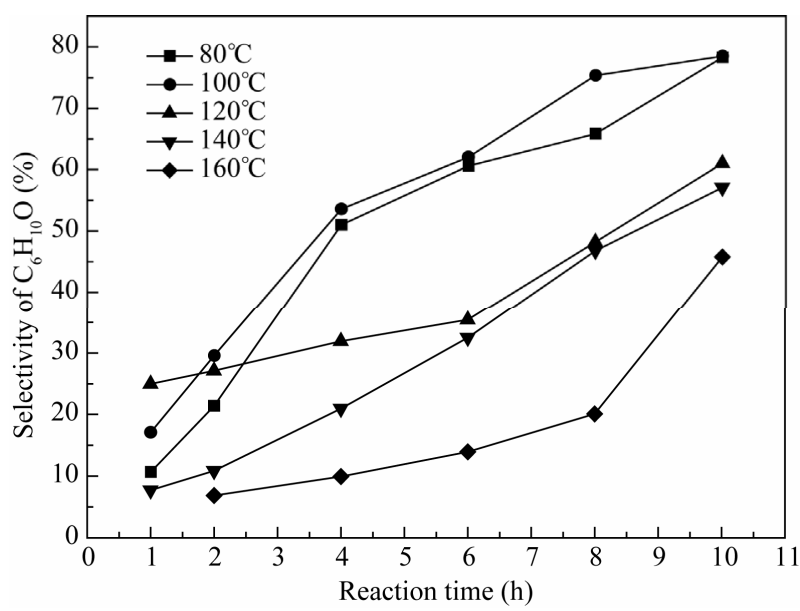

Figure 8. Selectivity of cyclohexene epoxide over the prepared Ti-SBA-15 samples.

selectivity than that of the sample synthesized at $80^{\circ} \mathrm{C}$ and both the efficiencies of them obvious higher than those of the others. Then, the catalytic efficiency decreasedremarkably with the increase of synthesis temperatures. The highest selectivity of cyclohexene epoxide was only about $44 \%$ for Ti-SBA- 15 synthesized at $160^{\circ} \mathrm{C}$. While the value was about $77 \%$ for Ti-SBA-15 synthesized at $100^{\circ} \mathrm{C}$ under the same reaction conditions. This indicated that increasing the synthesis temperatures can promote the catalytic efficiency of Ti-SBA-15 composite catalysts to some extent, but it is not always so. From the DR UV-vis spectra, we know that low synthesis temperatures promoted the form of Ti-O-Si which was the active center. Thus, $100^{\circ} \mathrm{C}$ was the optimal synthesis temperature under the reaction conditions.

\section{Conclusions}

In the present work, a series of Ti-containing mesoporous catalysts, Ti-SBA-15 composite, has been synthesized via direct hydrothermal route and characterized by using various technologies. The influence of synthesis temperatures on the structure and catalytic properties of these materials has been studied. The results showed that the prepared composite retained the ordered mesoporous structure of SBA-15 and showed very good catalytic efficiency in the epoxidation of cyclohexene. The sample synthesized at $100^{\circ} \mathrm{C}$ exhibited the highest catalytic efficiency. Thus, $100^{\circ} \mathrm{C}$ was the optimal temperature for the direct synthesis of Ti-SBA-15 composite catalysts under the present conditions.

\section{Acknowledgements}

This work was partly financially supported by the Innovation Experiment Fund of Zhengzhou University (2010 cxsy090).

\section{REFERENCES}

[1] T. Sreethawong, Y. Yamada, T. Kobayashi and S. Yoshikaw, "Catalysis of Nanocrystalline Mesoporous $\mathrm{TiO}_{2}$ on Cyclohexene Epoxidation with $\mathrm{H}_{2} \mathrm{O}_{2}$ : Effects of Mesoporosity and Metal Oxide Additives," Journal of Molecular Catalysis A-Chemical, Vol. 241, No. 1-2, 2005, pp. 23-32.

[2] “Technical Data Sheet, Chemical Divisions," BASF Corporation, Florham Park, 1997.

[3] C. T. Kresge, M. E. Leonowicz, W. J. Roth, J. C. Vartuli and J. S. Beck, "Ordered Mesoporous Molecular Sieves Synthesized by a Liquid-Crystal Template Mechanism," Nature, Vol. 359, No. 6397, 1992, pp. 710-712. doi: $10.1038 / 359710 \mathrm{a} 0$

[4] G. Lapisardi, F. Chiker, F. Launay, J. P. Nogier and J. L. Bonardet, "Preparation, Characterisation and Catalytic Activity of New Bifunctional Ti-AlSBA15 Materials. Application to a "One-Pot" Green Synthesis of Adipic Acid from Cyclohexene and Organic Hydroperoxides," Microporous and Mesoporous Materials, Vol. 78, No. 2-3, 2005, pp. 289-295. doi:10.1016/j.micromeso.2004.10.012

[5] W. Wang, M. Song, Z. Y. Zhang and M. Richardson, "Synthesis and Characterization of High Nickel-Containing Mesoporous Silica via a Modified Direct Synthesis Method," Journal of Non-Crystalline Solids, Vol. 352, No. 21-22, 2006, pp. 2180-2186. doi:10.1016/j.jnoncrysol.2006.01.037

[6] C. Galacho, M. M. L. Ribeiro Carrott and P. J. M.Carrott, "Structural and Catalytic Properties of Ti-MCM-41 Synthesised at Room Temperature up to High Ti Content," Microporous and Mesoporous Materials, Vol. 100, No. $1-3,2007$, pp. 312-321.

doi:10.1016/j.micromeso.2006.11.018

[7] G. A. Eimer, S. G. Casuscelli, C. A. Chanquia, V. Elías, M. E. Crivello and E. R. Herrero, "The Influence of Ti-Loading on the Acid Behavior and on the Catalytic Efficiency of Mesoporous Ti-MCM-41 Molecular Sieves," Catalysis Today, Vol. 133, 2008, pp. 639-646. doi:10.1016/j.cattod.2007.12.096

[8] D. Y. Zhao, J. L. Feng, Q. S. Huo, N. Melosh, G. H. Fredrickson, B. F. Chmelka and G. D. Stucky, "Triblock Copolymer Syntheses of Mesoporous Silica with Periodic 50 to 300 Angstrom Pores," Science, Vol. 279, No. 5350, 1998, pp. 548-552. doi:10.1126/science.279.5350.548

[9] D. Y. Zhao, Q. S. Huo, J. L. Feng, B. F. Chmelka and G. D. Stucky, "Nonionic Triblock and Star Diblock Copolymer and Oligomeric Surfactant Syntheses of Highly Ordered Hydrothermally Stable Mesoporous Silica Structures," Journal of American Chemistry Society, Vol. 120, No. 24, 1998, pp. 6024-6036. doi:10.1021/ja974025i

[10] P. I. Ravikovitch and A.V. Neimark, "Characterization of Micro- and Mesoporosity in SBA-15 Materials from Adsorption Data by the NLDFT Method," Journal of Physical Chemistry B, Vol. 105, No. 29, 2001, pp. 6817-6823. doi:10.1021/jp010621u

[11] G. Lapisardi, F. Chiker, F. Launay, J. P. Nogier and J. L. 
Bonardet, "A 'One-Pot' Synthesis of Adipic Acid from Cyclohexene under Mild Conditions with New Bifunctional Ti-AlSBA Mesostructured Catalysts," Catalysis Communications, Vol. 5, No. 6, 2004, pp. 277-281. doi:10.1016/j.catcom.2004.03.005

[12] F. Chiker, J. P. Nogier, F. Launay and J. L. Bonardet, "New Ti-SBA Mesoporous Solids Functionnalized under Gas Phase Conditions: Characterisation and Application to Selective Oxidation of Alkenes," Applied Catalysis A-General, Vol. 243, No. 2, 2003, pp. 309-321. doi:10.1016/S0926-860X(02)00553-7

[13] E. P. Barrett, L. G. Joyner and P. P. Halenda, "The Determination of Pore Volume and Area Distributions in Porous Substances. I. Computations from Nitrogen Isotherms," Journal of American Chemistry Society, Vol. 73, No. 1, 1951, pp. 373-380. doi:10.1021/ja01145a126

[14] J. C. Hu, Y. D. Wang, L. F. Chen, R. Richards, W. M.Yang, Z. C. Liu and W. Xu, "Synthesis and Characterization of Tungsten-Substituted SBA-15: An Enhanced Catalyst for 1-Butene Metathesis," Microporous and Mesoporous Materials, Vol. 93, No. 1-3, 2006, pp. 158163. doi:10.1016/j.micromeso.2006.02.019

[15] Z. R. Zhang, J. S. Suo, X. M. Zhang and S. B. Li, "Synthesis, Characterization, and Catalytic Testing of WMCM-41 Mesoporous Molecular Sieves," Applied Catalysis A-General, Vol. 179, No. 1-2, 1999, pp. 11-19. doi:10.1016/S0926-860X(98)00310-X

[16] C. K. Jorgensen, and S. J. Lippard, "Progress in Inorgnnic Chemistry," Interscience, St Nom la Bretêche, 1970.

[17] C. Morterra, A. Zecchina and G. Costa, "Structure and Reactivity of Surfaces," Elsevier, Amsterdam, 1989.

[18] A. Zecchina, G. Spoto, S. Bordiga, M. Padovan, G. Leofanti and G. Petrini, "Proceedings of the Zeocat 90," Leipzig, Elsevier, 1990.

[19] T. Blasco, A. Corma, M. T. Navarro and J. P. Pariente, "Synthesis, Characterization, and Catalytic Activity of Ti-MCM-41 Structures," Journal of Catalysis, Vol. 156, No. 1, 1995, pp. 65-74. doi:10.1006/jcat.1995.1232

[20] A. Tuel, S. Gontier and R. Teissier, "Zirconium Containing Mesoporous Silicas: New Catalysts for Oxidation Reactions in the Liquid Phase," Chemical Communications, No. 5, 1996, pp. 651-652. doi:10.1039/cc9960000651

[21] A. R. Oki, Q. Xu, B. Shpeizer, A. Clearfield, X. Qiu, S. Kirumakki and S. Tichy, "Synthesis, Characterization and
Activity in Cyclohexene Epoxidation of Mesoporous $\mathrm{TiO}_{2}-\mathrm{SiO}_{2}$ Mixed Oxides," Catalysis Communications, Vol. 8, No. 6, 2007, pp. 950-956. doi:10.1016/j.catcom.2006.09.022

[22] L. M.Yang, Y. J. Wang, G. S. Luo and Y.Y. Dai, "Simultaneous Removal of Copolymer Template from SBA-15 in the Crystallization Process," Microporous and Mesoporous Materials, Vol. 81, No. 1-3, 2005, pp. 107-114. doi:10.1016/j.micromeso.2005.01.023

[23] X. L.Yang, W. L. Dai, H. Chen, J. H. Xu, Y. Cao, H. X. Li and K. N. Fan, "Novel Tungsten-Containing Mesoporous HMS Material: Its Synthesis, Characterization and Catalytic Application in the Selective Oxidation of Cyclopentene to Glutaraldehyde by Aqueous $\mathrm{H}_{2} \mathrm{O}_{2}$," Applied Catalysis A-General, Vol. 283, No. 1-2, 2005, pp. 1-8. doi:10.1016/j.apcata.2004.12.029

[24] G. A. Eimer, S. G. Casuscelli, G. E. Ghione, M. E. Crivello and E. R .Herrero, "Synthesis, Characterization and Selective Oxidation Properties of Ti-Containing Mesoporous Catalysts," Applied Catalysis A-General, Vol. 298, 2006, pp. 232-242. doi:10.1016/j.apcata.2005.10.006

[25] V. Parvulescu, C. Anastasescu, C. Constantin and B. L. $\mathrm{Su}$, "Mono $(\mathrm{V}, \mathrm{Nb})$ or Bimetallic $(\mathrm{V}-\mathrm{Ti}, \mathrm{Nb}-\mathrm{Ti})$ Ions Modified MCM-41 Catalysts: Synthesis, Characterization and Catalysis in Oxidation of Hydrocarbons (Aromatics and Alcohols)," Catalysis Today, Vol. 78, No. 1-4, 2003, pp. 477-485. doi:10.1016/S0920-5861(02)00330-9

[26] P. Wu, T. Tatsumi, T. Komatsu and T. Yashima, "A Novel Titanosilicate with MWW Structure: II. Catalytic Properties in the Selective Oxidation of Alkenes," Journal of Catalysis, Vol. 202, No. 2, 2001, pp. 245- 255. doi:10.1006/jcat.2001.3278

[27] X. Gao and I. E. Wachs, "Titania-Silica as Catalysts: Molecular Structural Characteristics and Physico-Chemical Properties," Catalysis Today, Vol. 51, No. 2, 1999, pp. 233-254. doi:10.1016/S0920-5861(99)00048-6

[28] H. Kochkar and F. Figueras, "Synthesis of Hydrophobic $\mathrm{TiO}_{2}-\mathrm{SiO}_{2}$ Mixed Oxides for the Epoxidation of Cyclohexene," Journal of Catalysis, Vol. 171, No. 2, 1997, pp. 420-430. doi:10.1006/jcat.1997.1820

[29] M. A. Uguina, D. P. Serrano, G. Ovejero, R. Van Grieken. and M. Camacho, "Preparation of TS-1 by Wetness Impregnation of Amorphous $\mathrm{SiO}_{2}-\mathrm{TiO}_{2}$ Solids: Influence of the Synthesis Variables," Applied Catalysis A-General, Vol. 124, No. 2, 1995, pp. 391-408. doi:10.1016/0926-860X(95)00007-0 